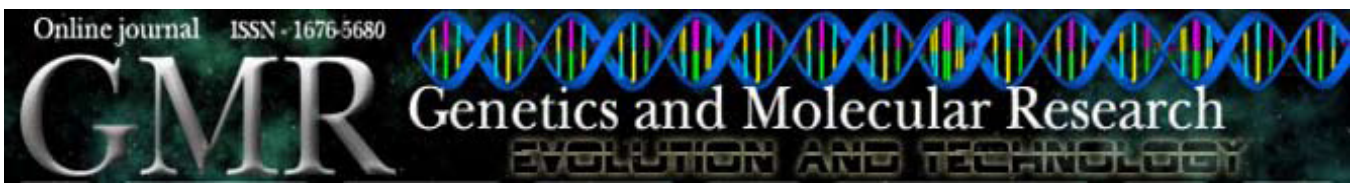

\title{
Development and use of single nucleotide polymorphism markers for candidate resistance genes in wild peanuts (Arachis spp)
}

\author{
D.M.T. Alves ${ }^{1}$, R.W. Pereira ${ }^{1}$, S.C.M. Leal-Bertioli ${ }^{2}$, M.C. Moretzsohn' ${ }^{2}$, \\ P.M. Guimarães ${ }^{2}$ and D.J. Bertioli ${ }^{1}$ \\ 'Pós-Graduação em Ciências Genômicas e Biotecnologia, \\ Universidade Católica de Brasília, Campus II, SGAN 916, Brasília, DF, Brasil \\ ${ }^{2}$ Embrapa Recursos Genéticos e Biotecnologia, Brasília, DF, Brasil \\ Corresponding author: D.M.T. Alves \\ E-mail: dionebio@gmail.com
}

Genet. Mol. Res. 7 (3): 631-642 (2008)

Received May 9, 2008

Accepted June 20, 2008

Published July 15, 2008

\begin{abstract}
The cultivated peanut (Arachis hypogaea L.) is an allotetraploid of recent origin, with an AABB genome and low genetic diversity. Perhaps because of its limited genetic diversity, this species lacks resistance to a number of important pests and diseases. In contrast, wild species of Arachis are genetically diverse and are rich sources of disease resistance genes. Consequently, a study of wild peanut relatives is attractive from two points of view: to help understand peanut genetics and to characterize wild alleles that could confer disease resistance. With this in mind, a diploid population from a cross between two wild peanut relatives was developed, in order to make a dense genetic map that could serve as a reference for peanut genetics and in order to characterize the regions of the Arachis genome that code for disease resistance. We tested two methods for developing and genotyping single nucleotide polymorphisms in candidate genes for disease resistance; one is based on single-base primer extension methods and the other is based on amplification refractory mutation system-polymerase chain reaction. We found single-base pair extension to be an efficient method, suitable for high-throughput, single-nucleotide polymorphism mapping; it allowed us to locate five
\end{abstract}


candidate genes for resistance on our genetic map.

Key words: Single nucleotide polymorphisms; Molecular markers; Arabidopsis disease resistance genes; Arachis; Genetic mapping

\section{INTRODUCTION}

Cultivated peanut (Arachis hypogaea) is an important crop for the production of oil and as a nutritional ingredient of human and animal foods. It is one of the main sources of protein in Africa and Asia (Savage and Keenan, 1994). Peanut is susceptible to a number of diseases, which increase costs and reduce yields for the farmer. For many of these diseases, good sources of resistance are lacking in cultivated germplasm, which has a very narrow genetic base (Kochert et al., 1991). This is probably because cultivated peanut originated from a single allotetraploidization event in a hybrid between two wild diploid species, most probably A. duranensis and A. ipaënsis (Kochert et al., 1996; Seijo et al., 2004, 2007). The resulting plant contains two distinct genomic components, known as AA and BB; it was reproductively isolated from its wild relatives, preventing gene flow and introgression of wild alleles. This narrow genetic base has also hampered the development of genetic maps and makes it difficult to use the tools available for genomic characterization and molecular breeding (Halward et al., 1991; Kochert et al., 1996; Herselman, 2003; Moretzsohn et al., 2004). On the other hand, the wild diploid species have greater genetic variability, accumulated over millions of years of evolution (Burow et al., 2001; Moretzsohn et al., 2004; Milla et al., 2005), and they are a rich source of genes for disease resistance and adaptation to diverse environments (Stalker and Simpson, 1995; Rao et al., 2003; Dwivedi et al., 2003, 2007).

More information about diploid Arachis genomes would therefore be useful, both to help simplify the construction of genetic and physical maps and for the characterization of wild alleles (Guimarães et al., 2008). With this in mind, we recently developed a microsatellite-based map for the AA genome of Arachis, based on a cross between A. stenosperma and A. duranensis (Moretzsohn et al., 2005). We chose microsatellites because they are polymerase chain reaction (PCR)based markers, are codominant and are highly transferable between Arachis species. The information content of this map could be improved by the mapping of candidate genes. Candidate genes are genes that, based on homology, expression or other data, are likely to be located in regions that control characteristics of interest. Although candidate genes have high value, they often present low levels of polymorphism as they are relatively conserved. With this in mind, we targeted single nucleotide polymorphisms (SNPs), the most abundant of all marker types (Douabin-Gicquel et al., 2001). Although the development of SNP markers is in principle possible using a number of methods, this option tends to be labor intensive, expensive and difficult to apply efficiently to identify multiple markers. Perhaps for these reasons, they have been relatively little used to date in plant genetics. We tested two different methods for developing SNP markers and analyzed their suitability, efficiency, and large-scale application.

\section{MATERIAL AND METHODS}

\section{DNA extraction}

DNA samples of Arachis stenosperma (accession \#10309), A. duranensis (acces- 
sion \#7988), the $\mathrm{F}_{1}$ hybrid and $93 \mathrm{~F}_{2}$ individuals were extracted using the method of Doyle and Doyle (1987), with minor modifications. DNA concentrations were estimated by agarose gel electrophoresis, comparing the fluorescence intensities of the ethidium bromidestained samples to DNA mass standards.

\section{Selection of sequences and primer design}

Ten Arachis expressed sequence tag (EST) sequences with homologies of interest were selected for primer development (Table 1). Homologies were detected using Blastx, E-values $<1 \mathrm{e}-10$. Eight are homologs of Arabidopsis-NBS-encoding genes, one is a homolog to a dehydration-responsive element, and another is a homolog of glutathione S-transferase (Proite et al., 2007; Nobile et al., 2008).

Primers were developed for the sequences above using the software Primer3 (http:// frodo.wi.mit.edu/) (Table 1).

\begin{tabular}{|c|c|c|c|}
\hline Sequence & Genbank & Blastx homology & E-value \\
\hline AS1RM11B11 & ЕH044444 & protein kinase, putative (RGA) & $1 \mathrm{E}-73$ \\
\hline AS1RM11G07 & ЕH044499 & MEK map kinase kinase (RGA) & $5 \mathrm{E}-49$ \\
\hline AS1RN7G02 & EH044037 & protein kinase-like protein (RGA) & $1 \mathrm{E}-35$ \\
\hline AS1RN33D02 & EH043336 & expressed protein (RGA) & $5 \mathrm{E}-73$ \\
\hline AS1RN36B01 & EH043571 & octicosapeptide/Phox/Bem1p (PB1) domain (RGA) & $4 \mathrm{E}-22$ \\
\hline AS1RN36E06 & EH043608 & disease resistance protein (TIR-NBS-LRR) (RGA) & $2 \mathrm{E}-20$ \\
\hline AS1RN39A08 & ЕH043651 & disease resistance protein-like (RGA) & $9 \mathrm{E}-13$ \\
\hline AS1RN25D07 & EH042682 & lectin-like protein kinase (RGA) & $3 \mathrm{E}-37$ \\
\hline AS1RN0x727 & EH044973 & dehydration-induced protein ERD15 & $5 \mathrm{E}-27$ \\
\hline AHBGSI1001D05 & EL966988 & glutathione S-transferase GST 8 [Glycine $\max ]$ & $4 \mathrm{E}-29$ \\
\hline
\end{tabular}

Homologies were detected using Blastx, E-values <1E-10. Eight are homologs of Arabidopsis-NBS-encoding resistance gene analogues (RGA), one is a homolog to a dehydration-responsive element and another is a homolog of glutathione S-transferase.

\section{Detection of polymorphism in progenitors}

PCR was performed in an Eppendorf MasterCycle using a "touchdown" program: 12 min at $95^{\circ} \mathrm{C}$, followed by 11 cycles of $15 \mathrm{~s}$ at $95^{\circ} \mathrm{C}, 15 \mathrm{~s}$ at $62^{\circ} \mathrm{C}$ (reduced by $1{ }^{\circ} \mathrm{C}$ per cycle), $30 \mathrm{~s}$ at $72^{\circ} \mathrm{C}$, followed by 35 cycles of $15 \mathrm{~s}$ at $95^{\circ} \mathrm{C}, 15 \mathrm{~s}$ at $52^{\circ} \mathrm{C}, 30 \mathrm{~s}$ at $72^{\circ} \mathrm{C}$, and a final extension of $10 \mathrm{~min}$ at $72^{\circ} \mathrm{C}$. In a total volume of $12 \mu \mathrm{L}, 5.0 \mathrm{ng}$ DNA, 1 X PCR buffer, $1.5 \mathrm{mM} \mathrm{MgCl}{ }_{2}, 0.2 \mathrm{mM}$ of each forward and reverse primers, $0.25 \mathrm{mM}$ dNTPs, and $0.4 \mathrm{U}$ platinum Taq DNA polymerase were used. PCR products were resolved on $6 \%$ nondenaturing polyacrylamide gels and visualized by silver staining (Creste et al., 2001; Sambrook and Russell, 2001). Amplification products that did not show length polymorphism between the progenitors were selected for sequencing.

\section{Sequencing and SNP detection}

Sequencing was performed directly from the PCR products using the BigDye Terminator sequencing kit (Applied Biosystems, CA, USA) on an ABI377 sequencer (Applied 
Biosystems). Sequences were processed using the Staden Package, and base calling was done using Phred (Ewing and Green, 1998; Staden et al., 2003). The sequences from the two parental alleles were included in the same contig, and SNPs were detected using the detect SNP candidate option and by manual inspection.

\section{SNP genotyping}

Two methods were used for genotyping SNPs. The first was tetra-primer amplification refractory mutation system (ARMS)-PCR (Ye et al., 2001), and the second was single-base extension (SBE), also known as minisequencing (Syvanen et al., 1990; Murphy et al., 2003). Both techniques produce codominant markers and are based on PCR.

\section{Testing SNP genotyping with tetra-primer ARMS-PCR}

In this method, two pairs of primers were designed using the allele sequences and an identified SNP (Figure 1). Two internal primers that face "outwards" were designed to bind specifically to one of the parental alleles, while two external primers facing "inwards" were designed to bind to both alleles. Both the internal primers were designed to have a miss-paired base at the penultimate 3' position. The external primers were placed at unequal distances from the internal ones. The primer design was done using the program tetra-primer ARMS-PCR, available at http://cedar.genetics.soton.ac.uk/public_html/primerl.html (Ye et al., 2001). PCR products were visualized on silver-stained 6\% polyacrylamide gel electrophoresis (Creste et al., 2001).

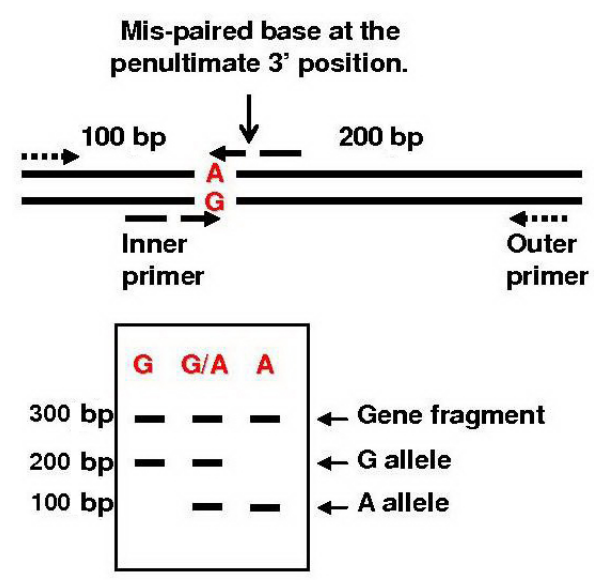

Figure 1. Illustrative demonstration of single nucleotide polymorphism identification using the tetra-primer amplification refractory mutation system-polymerase chain reaction methods. Four primers are designed for each marker in this method, two internal primers that bind specifically for one of the parental alleles, and two external primers that bind to both alleles. Both the internal primers are designed to have a miss-paired base at the penultimate 3' position, and the external primers are placed at unequal distances from the internal ones (Ye et al., 2001).

This method was initially tested on the progenitors of the AA genome mapping population and the $\mathrm{F}_{1}$. A pre-amplification was done using the original primers used for amplifica- 
tion of the alleles (Table 1). A second PCR was done using $1 \mu \mathrm{L}$ of "pre-amp" diluted 1:100; 10 pmol inner primers and 1 pmol of outer primers; 1 X PCR buffer; $1.5 \mathrm{mM} \mathrm{MgCl}, 1.6 \mathrm{mM}$ BSA, $0.25 \mathrm{mM}$ dNTPs; $0.4 \mathrm{U}$ platinum Taq DNA polymerase (Invitrogen). The final volume was completed to $12 \mu \mathrm{L}$ with autoclaved Milli-Q purified water. Thermocycling was done in an Eppendorf MasterCycler as follows: $2 \mathrm{~min}$ at $95^{\circ} \mathrm{C}$; followed by 35 cycles of $15 \mathrm{~s}$ at $95^{\circ} \mathrm{C}$, $20 \mathrm{~s}$ at the annealing temperature specific to each primer (Table 2), and $30 \mathrm{~s}$ at $72^{\circ} \mathrm{C}$, followed by a final extension of $5 \mathrm{~min}$ at $72^{\circ} \mathrm{C}$. PCR products were visualized on silver-stained $6 \%$ polyacrylamide gel electrophoresis (Creste et al., 2001).

\begin{tabular}{|c|c|c|c|}
\hline Genetic polymorphism & Multiplex primer sequences $\left(5^{\prime} \rightarrow 3^{\prime}\right)$ & $\begin{array}{l}\text { Annealing } \\
\text { temperature }\end{array}$ & $\begin{array}{l}\text { Amplicon } \\
\text { size }\end{array}$ \\
\hline $\begin{array}{l}\mathrm{AS} 1 \mathrm{RM} 1 \mathrm{P} 1 \mathrm{~B} 11 \\
\mathrm{G} \rightarrow \mathrm{A}\end{array}$ & $\begin{array}{l}\text { Forward inner primer (G allele) } \\
\text { GCTGAAGGTCAGGAACGATTAATT } \underline{T} \mathrm{TG} \\
\text { Reverse inner primer (A allele) } \\
\text { TAGGCTCAAATTCGGCATGTAGTCA } \underline{G A T} \\
\text { Forward outer primer } \\
\text { AAGTTGAGATATTGGCAAGGGTTCGA } \\
\text { Reverse outer primer } \\
\text { CCAATCAAGAAGGCTTTCAGCTGAGT }\end{array}$ & $57.3^{\circ} \mathrm{C}$ & $\begin{array}{c}\text { G allele: } 103 \mathrm{bp} \\
\text { A allele: } 113 \mathrm{bp} \\
\text { Two outer primers: } \\
161 \mathrm{bp}\end{array}$ \\
\hline $\begin{array}{l}\text { AS1RN7P1G02 } \\
\mathrm{A} \rightarrow \mathrm{C}\end{array}$ & $\begin{array}{l}\text { Forward inner primer (A allele) } \\
\text { AAAGGTCAAGCCCAACAGCAGCA } \underline{A} \mathrm{CA} \\
\text { Reverse inner primer (C allele) } \\
\text { GCACTTGGCTCTGCAAGGAAGAGG } \underline{\mathrm{T}} \mathrm{G} \\
\text { Forward outer primer } \\
\text { GTTCCGGAATCTTGCGATTCAAAATGGA } \\
\text { Reverse outer primer } \\
\text { ATGCCTGATAGCCCCTAACAGCCTTGGT }\end{array}$ & $62^{\circ} \mathrm{C}$ & $\begin{array}{l}\text { A allele: } 200 \mathrm{bp} \\
\text { C allele: } 181 \mathrm{bp} \\
\text { Two outer primers: } \\
328 \mathrm{bp}\end{array}$ \\
\hline $\begin{array}{l}\mathrm{AS} 1 \mathrm{RN} 36 \mathrm{P} 2 \mathrm{~B} 01 \\
\mathrm{G} \rightarrow \mathrm{A}\end{array}$ & $\begin{array}{l}\text { Forward inner primer (G allele) } \\
\text { TTGACCGTAGAATTGACTTCACAGCC } \underline{\text { TGG }} \\
\text { Reverse inner primer (A allele) } \\
\text { CAAAGAGGCTGGAGATTTCGGCACCT } \\
\text { Forward outer primer } \\
\text { GAGATCGACCGAGCAAAGTTCCTCTGC } \\
\text { Reverse outer primer } \\
\text { TTGATCGAACATGAGCATCATGTTGTGG }\end{array}$ & $60.5^{\circ} \mathrm{C}$ & $\begin{array}{l}\text { G allele: } 177 \mathrm{bp} \\
\text { A allele: } 160 \mathrm{bp} \\
\text { Two outer primers: } \\
282 \mathrm{bp}\end{array}$ \\
\hline $\begin{array}{l}\text { AS1RN36P2E06 } \\
\mathrm{T} \rightarrow \mathrm{C}\end{array}$ & $\begin{array}{l}\text { Forward inner primer (T allele) } \\
\text { GAGTGACTGCACAAGTTAATGAGT } \underline{G} \text { TT } \\
\text { Reverse inner primer (C allele) } \\
\text { TGAAGATATACCGAATACAGTGATG } \underline{T G G} \\
\text { Forward outer primer } \\
\text { GTTTTTCTAATTGTGCAACAGTGTCTG } \\
\text { Reverse outer primer } \\
\text { ATTGAAGAAATGGAATGGTAACCTAAGC }\end{array}$ & $55.3^{\circ} \mathrm{C}$ & $\begin{array}{c}\text { T allele: } 203 \mathrm{bp} \\
\text { C allele: } 247 \mathrm{bp} \\
\text { Two outer primers: } \\
394 \mathrm{bp}\end{array}$ \\
\hline $\begin{array}{l}\text { AS1RN0x727 } \\
T \rightarrow C\end{array}$ & $\begin{array}{l}\text { Forward inner primer (T allele) } \\
\text { TTGGAAACTAAAGGATTTTGGTCC } \underline{\mathrm{CTT}} \\
\text { Reverse inner primer (G allele) } \\
\text { TGTGGATCCTTTGAATTCAAAGA } \underline{\mathrm{GGG}} \\
\text { Forward outer primer } \\
\text { AATTGAGAATTTCGTTTTTCCTTTTTGG } \\
\text { Reverse outer primer } \\
\text { TCAGATCTCAGATCAAAATTCAAAACCA }\end{array}$ & $56.2^{\circ} \mathrm{C}$ & $\begin{array}{l}\text { T allele: } 174 \text { bp } \\
\text { C allele: } 195 \mathrm{bp} \\
\text { Two outer primers: } \\
316 \mathrm{bp}\end{array}$ \\
\hline
\end{tabular}

Each primer set comprises two internal primers, designed to bind specific to the SNP (in bold), and to have a misspaired base at the penultimate 3 ' position (italic underlined). 


\section{Single-base extension multiplex genotyping using the SNaPShot ${ }^{\circledR}$ kit}

With this technique, the primers were designed to bind to the DNA immediately adjacent to the SNP (Figure 2). A "tail" consisting of (dGACT), varying in size between 25 and $56 \mathrm{bp}$, was added to the 5 '-end of the primer. Different sizes of primers that bound to different SNPs could thus be used in multiplex. During the reaction, the ddNTP terminator corresponding to the allele present was incorporated and the genotype was read as a peak of fluorescence. Alleles were differentiated by size and color of fluorescence, as detected in capillary electrophoresis. Primers were designed using the Program Primo SNP 3.4: available at http://www.changbioscience.com/ primo/primosnp.html (Chang Bioscience).

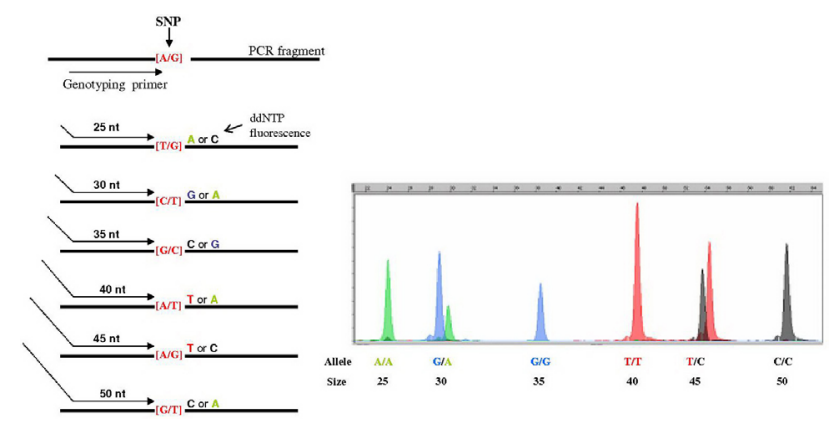

Figure 2. Illustrative demonstration of single nucleotide polymorphism (SNP) identification using the single nucleotide primer extension methods. For this technique, the primers are designed to bind to the DNA immediately adjacent to the SNP. A "tail" of (dGACT $)_{n}$ is added to the 5 '-end of the primer, varying in size. ddNTP terminator corresponding to the allele present is incorporated and the genotype is read as a peak of fluorescence. Alleles are differentiated by size and color of fluorescence as detected in capillary electrophoresis. PCR $=$ polymerase chain reaction.

Hairpin and primer dimer formation can potentially impair PCR efficiency and multiplexing. Therefore, all designed primers were checked for primer hairpin and dimer formation with Autodimer, an algorithm that was developed specifically to maximize multiplexing success (Vallone and Butler, 2004).

The PCR was performed in singleplex, using the same protocol described in "Detection of polymorphism in progenitors". Enzymatic purification of dNTPs and primers was carried out in $3 \mu \mathrm{L}$ PCR mix of all singleplex, by adding $0.4 \mathrm{U}$ ExoI, $1.0 \mathrm{U}$ shrimp alkaline phosphatase and incubating at $37^{\circ} \mathrm{C}$ for $90 \mathrm{~min}$. To achieve enzyme denaturation, reactions were incubated at $80^{\circ} \mathrm{C}$ for $20 \mathrm{~min}$. The minisequencing was performed using $1.0 \mu \mathrm{L} \mathrm{SNaPShot}{ }^{\mathbb{B}}$ multiplex minisequencing kit reaction mix (Applied Biosystems), $1 \mu \mathrm{L}$ purified PCR product, $0.4 \mu \mathrm{L}$ multiplex primer mix containing $0.133 \mu \mathrm{M}$ of each SBE primer, and sterile autoclaved Milli-Q water up to a final volume of $5 \mu \mathrm{L}$. SBE was performed as follows: 2 min at $96^{\circ} \mathrm{C}$, followed by 30 cycles of $20 \mathrm{~s}$ at $96^{\circ} \mathrm{C}, 20 \mathrm{~s}$ at $55^{\circ} \mathrm{C}$ (reduced by $0.5^{\circ} \mathrm{C}$ per cycle), $30 \mathrm{~s}$ at $60^{\circ} \mathrm{C}$, followed by 15 cycles of $15 \mathrm{~s}$ at $96^{\circ} \mathrm{C}, 20 \mathrm{~s}$ at $40^{\circ} \mathrm{C}, 30 \mathrm{~s}$ at $60^{\circ} \mathrm{C}$, without a final extension. SBE products were enzymatically purified in order to degrade fluorescent ddNTP not incorporated in the reaction by adding $0.5 \mathrm{U}$ shrimp alkaline phosphatase for each reaction, followed by incubation at $37^{\circ} \mathrm{C}$ for $60 \mathrm{~min}$ and then $75^{\circ} \mathrm{C}$ for $15 \mathrm{~min}$. Samples to be electrophoresed were prepared by adding $1 \mu \mathrm{L}$ purified SBE products in $8.9 \mu \mathrm{L}$ Hi-Di formamide and $0.10 \mu \mathrm{L} \mathrm{GS120} \mathrm{Liz} \mathrm{internal} \mathrm{size} \mathrm{standard.} \mathrm{Samples}$ were electrophoresed on an ABI prism 3100 Genetic Analyzer (Applied Biosystems), setting the 
equipment to use the SNP36_POP4 default module.

The electropherograms were analyzed with GeneMapper 3.5 or Genescan Analysis 3.7/Genotyper 3.7 software (Applied Biosystems).

\section{Mapping}

The linkage analysis was done using the Mapmaker MacIntosh, version 2.0 (Lander et al., 1987), essentially as described in Moretzsohn et al. (2005).

\section{RESULTS}

\section{Polymorphism detection}

Low levels of size polymorphism of PCR products were detected among the A. stenosperma $\mathrm{V} 10309$ and A. duranensis K7988, using the primers designed for the EST sequences. Only AHBGSI1001D05_I1 was polymorphic in size between the mapping progenitors. The other nine were monomorphic (data not shown).

\section{SNP identification}

SNPs were identified in all nine size monomorphic sequences. Five of them were chosen to design primers using the tetra-primer ARMS-PCR methodology. Eight of them were selected to design primers using the SBE primer methods.

\section{Tetra-primer ARMS-PCR}

The five SNPs selected to be genotyped using ARMS-PCR were AS1RM11P1B11, AS1RN7P1G02, AS1RN36P2B01, AS1RN36P2E06, and AS1RN0x727. The tetra-primers from each SNP are described in Table 2. Each tetra-primer was checked to see if it was free of hairpins and dimer formation, using Autodimer.

Two of the five tetra-primer amplifications showed bands as expected, two showed dominant bands and one was monomorphic (Figure 3).

A

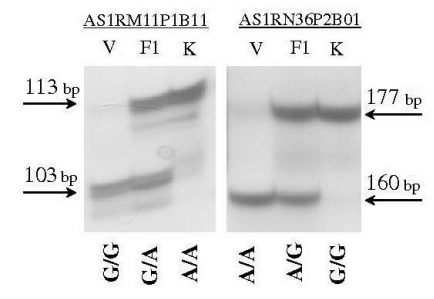

B

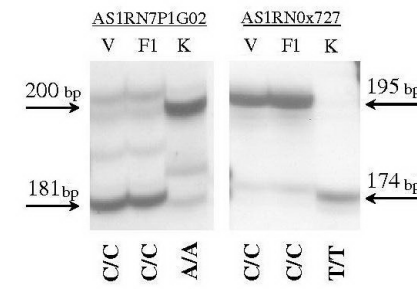

C

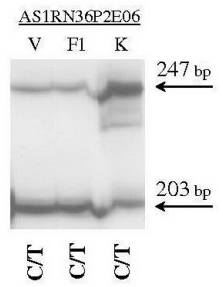

Figure 3. Profiles of bands obtained using tetra-primer amplification refractory mutation system-polymerase chain reaction using progenitor DNAs of the Arachis AA genome mapping population K (A. duranensis $\mathrm{K} 7988)$, V (A. stenosperma - V10309) and $\mathrm{F}_{1}$ (V10309 x K7988) on 5\% polyacrylamide gel, stained with silver nitrate. Products from the two external primers, which are present in all reactions, are not shown. A. Bands as expected were produced for AS1RN36B01 and AS1RM11B11. B. Dominant bands were produced from AS1RN7G02 and AS1RN0x727. C. A monomorphic band was observed with AS1RN36E06. 


\section{Single-base primer extension - SNaPShot ${ }^{\circledR}$}

Eight primers were designed using SBE methods. All of them were checked to determine if they were free of hairpins and dimer formation with Autodimer. The primers are described in Table 3.

$\begin{aligned} & \text { Table 3. Eight single-base extension primers for SNaPShot }{ }^{\circledR} \text { multiplex reaction, DNA strand direction, primer } \\
& \text { size, and reference alleles. }\end{aligned}$
\begin{tabular}{lllcc}
\hline Sequence & Single-base extension primer $\left(5^{\prime} \rightarrow 3^{\prime}\right)$ & $\begin{array}{c}\text { Strand } \\
\text { direction }\end{array}$ & $\begin{array}{c}\text { Primer } \\
\text { size (bp) }\end{array}$ & $\begin{array}{c}\text { Reference } \\
\text { alleles (K/V) }\end{array}$ \\
\hline AS1RM11B11 & gactgacGTTCGGCATGTAGTCATA & Reverse & 25 & $\mathrm{~T} / \mathrm{C}$ \\
AS1RN33D02 & gactgactgacGGCTCTGGCTGCCC & Reverse & 25 & $\mathrm{~A} / \mathrm{G}$ \\
AS1RM11G07 & gactgactgactgactgaATCGCGCACATCAAGCT & Reverse & 35 & $\mathrm{G} / \mathrm{C}$ \\
AS1RN39A08 & gactgactgactgactgaAACACCGCTGATTACCA & Reverse & 35 & $\mathrm{~A} / \mathrm{T}$ \\
AS1RN7G02 & gactgactgactgactgactgaTTTGGCAGTGATCTTGGT & Reverse & 40 & $\mathrm{C} / \mathrm{T}$ \\
AS1RN36B01 & gactgactgactgactgactgacTCCACAACATGATGCTC & Forward & 40 & $\mathrm{G} / \mathrm{A}$ \\
AS1RN25D07 & gactgactgactgactgactgactgaAGTTCCTGTCCTCATGT & Forward & 44 & $\mathrm{~T} / \mathrm{C}$ \\
AS1RN0x727 & gactgactgactgactgactgactgactgactCGGCATACAGATCGGG & Reverse & 48 & $\mathrm{~T} / \mathrm{G}$ \\
\hline K
\end{tabular}

$\mathrm{K}=$ Arachis duranensis $-\mathrm{K} 7988 ; \mathrm{V}=$ A. stenosperma $-\mathrm{V} 10309$.

Only one SNP did not function as expected (AS1RN39A08). It showed a monomorphic peak. The other seven were genotyped in a single run. The peak height and fragment size of each allele of the seven genotyped SNPs are shown in Figure 4.

$\mathbf{A}$

A A ditranensis - K 7798

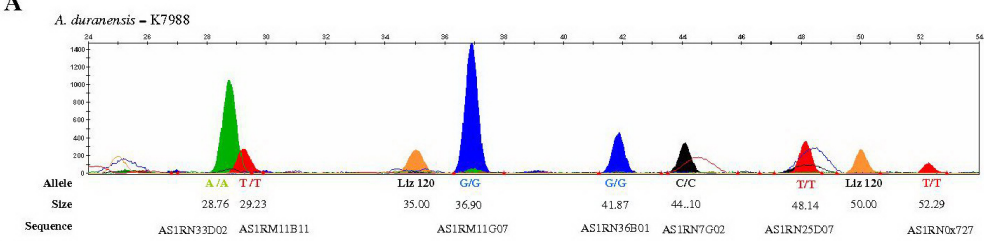

B

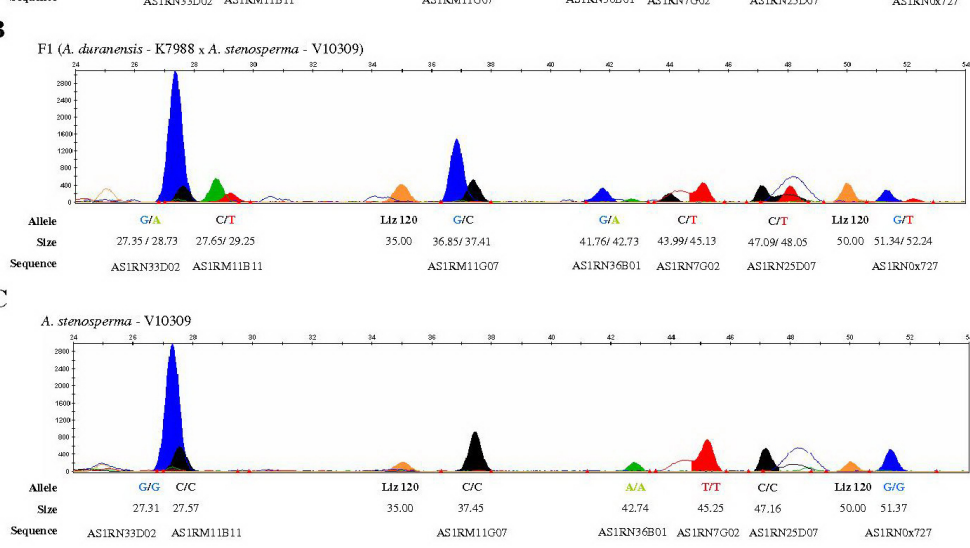

Figure 4. Electropherogram showing single-base extension primers for SNaPShot ${ }^{\circledR}$ multiplex reaction. Labels below peaks indicate allele calling. A. Parental Arachis duranensis - K7988 allele. B. Hybrid $\mathrm{F}_{1}$ (A. duranensis K7988 x A. stenosperma - V10309) allele. C. Parental A. stenosperma - V10309 allele. 


\section{Mapping}

Among the nine genotyped markers, five were incorporated into the AA genome linkage map, AS1RN7G02, AS1RN36B01, AS1RN25D07, AS1RN0x727, and AHBGSI1001D05_I1 (Figure 5). The other markers remained unlinked.

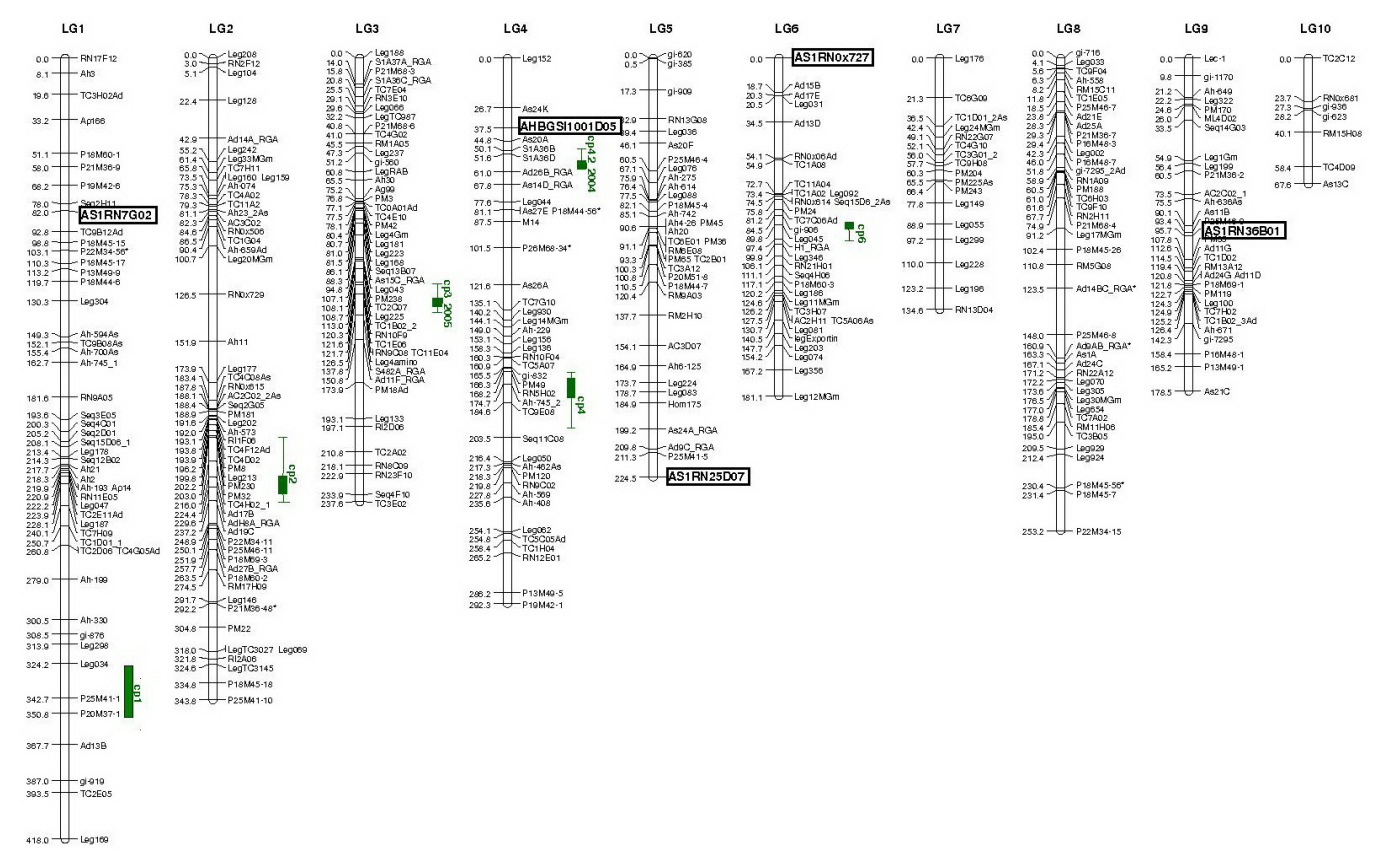

Figure 5. Peanut genetic linkage map obtained through the analysis of $93 \mathrm{~F}_{2}$ plants, generated from a cross between two diploid wild species with AA genome, Arachis duranensis and A. stenosperma (Moretzsohn et al., 2005). Five single nucleotide polymorphism markers were incorporated into the AA genome linkage map. In green, are QTL markers to resistance to late leaf spot in Arachis, caused by the fungus C. personatum.

\section{DISCUSSION}

Mapping of candidate genes improves the information content of the Arachis map. Candidate genes often present low levels of polymorphism, because they are often relatively conserved and because it is generally difficult to map these regions using markers based on size polymorphism. SNPs constitute the most abundant of molecular markers (Douabin-Gicquel et al., 2001). The high density and mutational stability of SNPs make them particularly useful DNA markers for population genetics and for mapping candidate genes for disease resistances and abiotic stress tolerance (Brookes, 1999). The use of SNPs in combination with a highly polymorphic population, such as the AA genome population in the interspecific cross used here, should allow a high rate of sequences to be mapped. We were able to identify SNP for all the sequences of interest, even though they were short fragments of coding regions.

Previously, we have used CAPs and dCAPs (Bertioli DJ, Moretzsohn MC, Madsen L, 
Sandal N, et al., unpublished data) to map SNP in Arachis, but the reliance on restriction enzymes makes these methods costly and time-consuming. The main aim of our current study was to test two restriction enzyme-free methods for genotyping SNPs, one based on SBE primer methods and the other based on ARMS-PCR.

As expected, size polymorphism of candidate gene regions between Arachis genotypes of interest was low. Only one candidate gene of nine was size polymorphic. However, SNPs were identified in all the remaining size-monomorphic sequences. In order to compare the SBE and ARMS-PCR methods, we selected eight and five size monomorphic sequences, respectively.

Of the five ARMS-PCR markers that we developed, two showed the expected band sizes, two showed dominant bands and one was monomorphic. We made substantial effort to optimize the PCR conditions, but without success. Consequently, the yield of functional markers was low (40\%). On the other hand, we found that the SBE method was more efficient and less time-consuming. Seven SNPs were genotyped in a single run on the automated sequencing machine, while only one of the eight SNPs showed a monomorphic peak. The peak height and fragment size of each allele were ideal to identify the alleles, to observe their segregation, and to validate and genotype the SNPs.

Among the 8 genotyped markers, five were incorporated into the AA genome linkage map: AS1RN7G02, AS1RN36B01, AS1RN25D07, AS1RN0x727, and AHBGSI1001D05_I1. The other markers remained unlinked. Markers AS1RN7G02, AS1RN36B01, AS1RN25D07 have homology to Arabidopsis disease resistance genes. It is well known that this type of gene frequently occurs in clusters (Michelmore and Meyers, 1998); as expected, one of them (AS1RN25D07) mapped close to two other resistance gene analogues at the bottom of LG5 (Moretzsohn et al., 2005). Another candidate gene with homology to glutathione S-transferase, AHBGSI1001D05_I1, identified in a study of gene expression in response to C. personatum, mapped close to a QTL for resistance against this disease (Leal-Bertioli et al., 2007). These observations, although limited in number, do begin to demonstrate the potential value of mapping candidate genes.

In conclusion, we found that the mapping of selected candidate genes in Arachis can be done quickly and efficiently with SBE. This methodology in combination with a highly polymorphic reference population makes mapping of the vast majority of sequences of interest feasible.

\section{ACKNOWLEDGMENTS}

The authors gratefully acknowledge the European Union Grain Legume Integrated Project (GLIP: FOOD-CT-2004-506223), and the Generation Challenge Program (Project \#31, and the TLI project) and host institutions for funding this research.

\section{REFERENCES}

Brookes AJ (1999). The essence of SNPs. Gene 234: 177-186.

Burow MD, Simpson CE, Starr JL and Paterson AH (2001). Transmission genetics of chromatin from a synthetic amphidiploid to cultivated peanut (Arachis hypogaea L.). Broadening the gene pool of a monophyletic polyploid species. Genetics 159: 823-837.

Creste S, Tulmann Neto A and Figueira A (2001). Detection of single sequence repeat polymorphisms in denaturing polyacrylamide sequencing gels by silver staining. Plant Mol. Biol. Repor. 19: 299-306.

Douabin-Gicquel V, Soriano N, Ferran H, Wojcik F, et al. (2001). Identification of 96 single nucleotide polymorphisms 
in eight genes involved in iron metabolism: efficiency of bioinformatic extraction compared with a systematic sequencing approach. Hum. Genet. 109: 393-401.

Doyle JJ and Doyle JL (1987). Isolation of plant DNA from fresh tissue. Focus 12: 13-15.

Dwivedi SI, Crouch JH, Nigam SN, Ferguson ME, et al. (2003). Molecular breeding of groundnut for enhanced productivity and food security in the semi-arid tropics: Opportunities and challenges. Adv. Agron. 80: 153-221.

Dwivedi SI, Bertioli DJ, Crouch JH, Valls JFM, et al. (2007). Peanut Genetics and Genomics: Toward Marker-Assisted Genetic Enhancement in Peanut (Arachis hypogaea L). In: Oilseeds Series: Genome Mapping and Molecular Breeding in Plants (Kole C, ed.). Oilseeds Series: Genome Mapping and Molecular Breeding in Plants. Vol. 2. Springer, Berlin, Heidelberg, 115-151.

Ewing B and Green P (1998). Base-calling of automated sequencer traces using Phred II. Error probabilities. Genome Res. 8: 186-194.

Guimarães PM, Garsmeur O, Proite K, Leal-Bertioli SCM, et al. (2008). BAC libraries construction from the ancestral diploid genomes of the allotetraploid cultivated peanut. BMC Plant Biol. 8: 1-8.

Halward TM, Stalker HT, Larue EA and Kochert G (1991). Genetic variation detectable with molecular markers among unadapted germplasm resources of cultivated peanut and related wild species. Genome 34: 1013-1020.

Herselman L (2003). Genetic variation among Southern African cultivated peanut (Arachis hypogaea L.) genotypes as revealed by AFLP analysis. Euphytica 1333: 319-327.

Kochert G, Halward T, Branch WD and Simpson CE (1991). RFLP variability in peanut (Arachis hypogaea) cultivars and wild species. Theor. Appl. Genet. 81: 565-570.

Kochert G, Stalker HT, Gimenes M, Galgaro L, et al. (1996). RFLP and cytogenetic evidence on the origin and evolution of allotetraploid domesticated peanut, Arachis hypogaea (Leguminosae). Am. J. Bot. 83: 1282-1291.

Lander ES, Green P, Abrahamson J, Barlow A, et al. (1987). MAPMAKER: an interactive computer package for constructing primary genetic linkage maps of experimental and natural populations. Genomics 1: 174-181.

Leal-Bertioli SCM, Moretzsohn MC, Jose ACVF, Guimarães PM, et. al. (2007). Comparison between AA- and BBgenome maps of Arachis and the co-localization of RGAs and QTLs for resistance to Cercosporidium personatum (Berk and Curt). In: 6th European Conference of Grain Legume and Grain Legume Integrated Platform Meeting (GLIP), 2007, Lisboa. Book of Abstracts. Available at http://www.grainlegumes.com.

Michelmore RW and Meyers BC (1998). Clusters of resistance genes in plants evolve by divergent selection and a birthand-death process. Genome Res. 8: 1113-1130.

Milla SR, Isleib TG and Stalker HT (2005). Taxonomic relationships among Arachis sect. Arachis species as revealed by AFLP markers. Genome 48: 1-11.

Moretzsohn MC, Hopkins MS, Mitchell SE, Kresovich S, et al. (2004). Genetic diversity of peanut (Arachis hypogaea L.) and its wild relatives based on the analysis of hypervariable regions of the genome. BMC Plant Biol. 4: 11 .

Moretzsohn MC, Leoi L, Proite K, Guimaraes PM, et al. (2005). A microsatellite-based, gene-rich linkage map for the AA genome of Arachis (Fabaceae). Theor. Appl. Genet. 111: 1060-1071.

Murphy KM, Geiger T, Hafez MJ, Eshleman JR, et al. (2003). A single nucleotide primer extension assay to detect the APC I1307K gene variant. J. Mol. Diagn. 5: 222-226.

Nobile PM, Lopes CR, Barsalobres-Cavallari C, Quecini VM, et al. (2008). Peanut genes identified during initial phase of Cercosporidium personatum infection. Plant Sci. 174: 78-87.

Proite K, Leal-Bertioli SC, Bertioli DJ, Moretzsohn MC, et al. (2007). ESTs from a wild Arachis species for gene discovery and marker development. BMC Plant Biol. 7: 7-17.

Rao NK, Reddy LJ and Bramel PJ (2003). Potential of wild species for genetic enhancement of some semi-arid food crops. Genet. Res. Crop Evol. 50: 707-721.

Sambrook J and Russell DW (2001). Molecular Cloning: A Laboratory Manual. Cold Spring Harbor Laboratory Press, New York.

Savage GP and Keenan JI (1994). The Composition and Nutritive Value of Groundnut Kernels. In: The Groundnut Crop - A Scientific Basis for Improvement (Smartt J, ed.). Chapman and Hall, London, 173-213.

Seijo GJ, Lavia GI, Fernández A, Krapovickas A, et al. (2004). Physical mapping of the 5S and 18S-25S rRNA genes by FISH as evidence that Arachis duranensis and A. ipaensis are the wild diploid progenitors of A. hypogaea (Leguminosae). Am. J. Bot. 91: 1294-1303.

Seijo GJ, Lavia GI, Fernández A, Krapovickas A, et al. (2007). Genomic relationships between the cultivated peanut (Arachis hypogaea, Leguminosae) and its close relatives revealed by double GISH. Am. J. Bot. 94: 1963-1971.

Staden R, Judge DP and Bonfield JK (2003). Managing Sequencing Projects in the GAP4 Envinroment. Introduction to Bioinformatics. A Theoretical and Practical Approach. Human Press Inc., Totawa.

Stalker HT and Simpson CE (1995). Germplasm resources in Arachis. In: Advances in Peanut Science (Pattee HE and Stalker HT, eds.). APRES, Stillwater, 14-53. 
Syvanen AC, Aalto-Setälä K, Harju L, Kontula K, et al. (1990). A primer-guided nucleotide incorporation assay in the genotyping of apolipoprotein E. Genomics 8: 684-692.

Vallone PM and Butler JM (2004). AutoDimer: a screening tool for primer-dimer and hairpin structures. Biotechniques 37: 226-231.

Ye S, Dhillon S, Ke X, Collins AR, et al. (2001). An efficient procedure for genotyping single nucleotide polymorphisms. Nucleic Acids Res. 29: E88. 